\section{REFERENCES}

1 Hasle H. Incidence of essential thrombocythaemia in children. Br J Haematol 2000; 110: 751.

2 Randi ML, Geranio G, Bertozzi I, Micalizzi C, Ramenghi U, Tucci F et al. Are all cases of paediatric essential thrombocythaemia really myeloproliferative neoplasms? Analysis of a large cohort. Br J Haematol 2015; 169: 584-589.

3 Nangalia J, Massie CE, Baxter EJ, Nice FL, Gundem G, Wedge DC et al. Somatic CALR mutations in myeloproliferative neoplasms with nonmutated JAK2. N Engl J Med 2013; 369: 2391-2405.

4 Fu R, Xuan M, Zhou Y, Sun T, Bai J, Cao Z et al. Analysis of calreticulin mutations in Chinese patients with essential thrombocythemia: clinical implications in diagnosis, prognosis and treatment. Leukemia 2014; 28: 1912-1914.

5 Giona F, Teofili L, Capodimonti S, Laurino M, Martini M, Marzella D et al. CALR mutations in patients with essential thrombocythemia diagnosed in childhood and adolescence. Blood 2014; 123: 3677-3679.

6 Langabeer SE, Haslam K, McMahon C. CALR mutations are rare in childhood essential thrombocythemia. Pediatr Blood Cancer 2014; 61: 1523.

7 Kucine N, Chastain KM, Mahler MB, Bussel JB. Primary thrombocytosis in children. Haematologica 2014; 99: 620-628.

8 Fu R, Zhang L, Yang R. Paediatric essential thrombocythaemia: clinical and molecular features, diagnosis and treatment. Br J Haematol 2013; 163: 295-302.

9 Tefferi A, Vardiman JW. Classification and diagnosis of myeloproliferative neoplasms: the 2008 World Health Organization criteria and point-of-care diagnostic algorithms. Leukemia 2008; 22: 14-22.

10 Fu R, Xuan M, Lv C, Zhang L, Li H, Zhang X et al. External validation and clinical evaluation of the International Prognostic Score of Thrombosis for Essential
Thrombocythemia (IPSET-thrombosis) in a large cohort of Chinese patients. Eur J Haematol 2014; 92: 502-509.

11 Tefferi A. Novel mutations and their functional and clinical relevance in myeloproliferative neoplasms: JAK2, MPL, TET2, ASXL1, CBL, IDH and IKZF1. Leukemia 2010; 24: 1128-1138.

12 Papaemmanuil E, Gerstung M, Malcovati L, Tauro S, Gundem G, Van Loo P et al. Clinical and biological implications of driver mutations in myelodysplastic syndromes. Blood 2013; 122: 3616-3627.

13 Bejar R, Stevenson K, Abdel-Wahab O, Galili N, Nilsson B, Garcia-Manero G et al. Clinical effect of point mutations in myelodysplastic syndromes. $N$ Engl J Med 2011; 364: 2496-2506.

14 Lundberg P, Karow A, Nienhold R, Looser R, Hao-Shen H, Nissen I et al. Clonal evolution and clinical correlates of somatic mutations in myeloproliferative neoplasms. Blood 2014; 123: 2220-2228.

15 Zhang X, Hu T, Wu Z, Kang Z, Liu W, Guan M. The JAK2 46/1 haplotype is a risk factor for myeloproliferative neoplasms in Chinese patients. Int J Hematol 2012; 96: 611-616.

\footnotetext{
This work is licensed under a Creative Commons AttributionNonCommercial-NoDerivs 4.0 International License. The images or By No ND license, unless indicated otherwise in the credit line; if the material is not included under the Creative Commons license, users will need to obtain permission from the license holder to reproduce the material. To view a copy of this license, visit http:// creativecommons.org/licenses/by-nc-nd/4.0/
}

\title{
Gene dosage reductions of Trf1 and/or Tin2 induce telomere DNA damage and lymphoma formation in aging mice
}

Leukemia (2016) 30, 749-753; doi:10.1038/leu.2015.173

Telomeres are essential structures that cap the end of chromosomes, which is required for maintenance of chromosomal stability, cell viability and the capacity of cells to proliferate. A complex of specific telomere-binding proteins (TRF1, TRF2, POT1, TIN2, TPP1 and RAP1), also known as the Shelterin complex, is essential for telomere capping by assisting the formation of tertiary telomeric structures. ${ }^{1}$ Gene mutations in components of the Shelterin complex ( $h$ TIN2, hPOT1 and hTPP1) lead to bone marrow failure and cancer formation in human genetic diseases including dyskeratosis congenita (DC), which is caused by Tin2 mutation in $20 \%$ of the cases. ${ }^{2,3}$ All known TIN2 mutations are heterozygous, autosomal-dominant and patients normally show extremely short telomeres. In addition, mutations in the telomere binding protein POT1 were shown to lead to lymphocytic leukaemia formation. ${ }^{4}$ Aside from genetic diseases, a variety of studies reported reduced expression of telomere-binding proteins in human cancers compared with non-cancerous tissue suggesting that downregulation of the expression of telomere-binding proteins may also contribute to carcinogenesis in somatic cells and tissues. ${ }^{5,6}$ It was shown that Epstein-Barr virus-encoded LMP1 and Epstein-Barr virus-infection itself induce the downregulation of TRF1, TRF2 and POT1 at the transcriptional and translational level resulting in complex chromosomal aberrations, alternative lengthening of telomeres and the induction of Hodgkin's lymphoma. ${ }^{7,8}$

The causal relation between gene dosage reductions of telomere binding protein and the development of cancer and tissue aging remains elusive. Mouse knockout studies revealed that homozygous deletions of Tin2 or Trf1 lead to early embryonic lethality. ${ }^{9,10}$ The conditional homozygous deletion of Trf1 was shown to provoke severe defects in tissue maintenance ${ }^{11}$ and in combination with homozygous p53 deletion led to cancer formation in skin. ${ }^{12}$ However, these models did not address the question of whether moderate reductions in the gene dose of telomere-binding proteins contribute to tissue aging and/or carcinogenesis. To address this question we followed aging cohorts of mice carrying heterozygous deletion of Trf1 and/or Tin2 in comparison with wild-type mice. ${ }^{9,10}$

Heterozygous Trf $^{+/}{ }^{+-}$Tin2 $^{+/-}$knockout mice showed a $40-50 \%$ reduction in the mRNA expression level of Trf1 and Tin2, but had no effect on the mRNA expression profile of other telomerebinding proteins (Figures 1a and b, Supplementary Figures 1a and d). Protein analysis of whole-spleen extracts revealed an $\sim 50 \%$ reduced Tin2 expression in Tin2 $2^{+/-}$mice compared with $\operatorname{Tin} 2^{+/+}$ mice (Figure 1c, Supplementary Figure 1e). Trusty antibodies for detection of endogenous Trf1 protein in tissues are still lacking. To monitor the Trf1 protein amounts in Trf1 heterozygous mice, a Trf1 hemagglutinin ( $\mathrm{HA}$ )-tag knockin mouse line was generated carrying the HA-tag at the $\mathrm{N}$-terminus of the endogenous Trf1 gene locus. Opposed to the homozygous Trf1 knockout mouse, homozygous HA-Trf1 knockin mice (Trf ${ }^{\mathrm{ki} / \mathrm{ki}}$ ) are viable, do not exhibit an overt organismal phenotype and show normal telomere structure indicating that the HA-tag did not interfere with Trf1 function. Trf1 protein from the knockin mice was quantitatively immunoprecipitated with an anti-HA antibody using equally concentrated lysates. Heterozygous Trf1 deletion led to a reduction in Trf1 protein amounts, whereas the heterozygous deletion of Tin2 had no significant impact on Trf1 protein levels 
(Figure 1d; Supplementary Figure 1f). As Trf1 binds directly to Tin2, the heterozygous Trf1 knockout mice $\left(\operatorname{Trf1} 1^{\mathrm{ki}-} \operatorname{Tin} 2^{+/+}\right.$) also exhibited a reduction in the amount of Trf1-bound Tin2 compared with $\mathrm{Trf}^{\mathrm{ki} / \mathrm{ki}} \mathrm{Tin}^{+/+}$mice (Figure 1d; Supplementary Figure 1f).

Immuno-fluorescence in situ hybridization staining of telomeres and telomere-binding proteins revealed that heterozygous deletion of Trf1 reduces the co-localization of Trf1 with telomeric DNA in $\mathrm{Trfl}^{+/-}$mice and in $\mathrm{Trfl}^{+/-} \mathrm{Tin2}^{+/-}$mice compared with $\mathrm{Trfl}^{+/+}$ control and Tin $2^{+/-}$mice (Figures $1 \mathrm{e}$ and f). Since Trf1 mediates binding of Tin2 at telomeres, heterozygous deletion of Trf1 also led to a reduced binding of Tin2 protein at telomeres compared to wild-type controls (Figures 1e and g). Heterozygous deletion of Tin2 reduced Tin2 localization at telomeres compared to wild-type mice but in agreement with the fact that Trf1 binds directly to telomeres Tin2 deletion did not affect Trf1 expression at telomeres (Figures 1e and f). The heterozygous gene deletions of Tin2 and/or Trf1 did not affect the Rap1 localization at telomeres, which is known to bind directly to telomeres in mammalian cells or through its interaction with Trf2 (Supplementary Figures $1 \mathrm{~g}$ and $\mathrm{h}$ ). Together, the data on protein expression showed that the heterozygous deletion of Trf1 and/or Tin2 lead to reduction of Trf1 and/or Tin2 expression and to reduced localization of the proteins at telomeres in murine cells and tissues.

Cohorts of single heterozygous knockout mice (Tin2 ${ }^{+/-}, n=21$ and $\mathrm{Trf1}^{+/-}, n=32$ ), double heterozygous knockout mice $\operatorname{Trf1}^{+/-} \operatorname{Tin}^{+/-} \quad(n=33)$ and wild-type mice $\left(\operatorname{Tin} 2^{+/+}, \operatorname{Trf1}^{+/+}\right.$, $n=26)$ were weekly monitored during aging and exhibited no overt premature aging phenotype (Figure $1 \mathrm{~h}$ ). Analysis of the bone marrow of a cohort of mice at the age of 14-16 months did not reveal evidence for bone marrow failure. Specifically, the Tin2 and/or Trf1 gene status did not affect the number of hematopoietic stem and progenitor cells in bone marrow (Figure 1i; Supplementary Figure 1i). Mice were humanly killed when showing $>15 \%$ of weight loss during aging or other apparent abnormalities (wounds and tumors). Knockout animals exhibited increased incidence of tumors infiltration of spleen, liver and lymph nodes. Kaplan-Meier analysis of tumor-free survival revealed a significant increase in tumor formation in the three cohorts of heterozygous and double-heterozygous knockout mice compared with the wildtype cohort (Figure 1j; Supplementary Figure 1j). Specifically, the analysis indicated that tumor formation in the heterozygous knockout cohorts was accelerated and occurred significantly earlier in life compared with the wild-type cohort.

Overall, $83.3 \%$ of the aged wild-type mice were free of tumors when humanly sacrificed due to aging characteristics. Histological analysis of macroscopic tumors revealed that in the wild-type cohort $13.3 \%$ of the mice had malignant tumors and $3 \%$ carried hyperplastic tumor nodules (Figure 1k). In contrast, 68\% (60-76\%) of the mice from single or double heterozygous knockout cohorts developed macroscopic tumors including malignant tumors in $54 \%$ of the mice $(52-56 \%)$ and the percentage of hyperplasia was increased to an average of 14\% (6.7-20\%, Figure 1k). Histological analysis of five representative malignant tumors of $\mathrm{Trf1}^{+/}$- $\mathrm{Tin}^{+/-}$ mice indicated that the majority of the malignant tumors were T- or B-cell lymphoma (Supplementary Figure 1k). Aside from the increased overall frequency, there was no significant shift in the spectrum of tumors in heterozygous or double-heterozygous knockout mice compared with the wild-type cohort.

Studies on telomerase deficient mice indicated that telomere shortening leads to an increase in chromosomal instability and tumor initiation. ${ }^{13}$ To analyze whether such mechanisms were involved in accelerating tumor formation in response to heterozygous deletion of telomere-binding proteins, we studied telomere stability and DNA damage at telomeres in bone marrow derived metaphase spreads of 14-16-month-old mice. Telomere length analysis showed shortening of telomeres from double heterozygous $\mathrm{Trf1}^{+/-}$Tin2 $^{+/-}$mice compared with wild-type mice (Figure 2a). In addition, telomeric fluorescence in situ hybridization analysis revealed increases in (i) broken telomeres (Figures $2 \mathrm{~b}$ and c) and (ii) multi-telomeric signals (Figures $2 \mathrm{~b}$ and $\mathrm{d}$ ), both are markers of fragile telomeres and replication stress. Moreover, sister chromatid exchange rates at telomeres (another feature of fragile telomeres) were increased in $\mathrm{Trfl}^{+/-}$and $\mathrm{Tin2}^{+/-}$as well as in double heterozygous mouse embryonic fibroblasts compared with wildtype mouse embryonic fibroblasts (Figures $2 e$ and f). To analyze whether telomere fragility would also lead to an accumulation of DNA damage, the number of 53BP1 DNA damage foci was analyzed in small intestine of 14-16-month-old mice. There was a significant increase in the number of intestinal epithelial cells in basal crypts harboring $53 \mathrm{BP}^{+}$DNA damage foci in the heterozygous mutant cohorts compared with control mice (Figures $2 \mathrm{~g}$ and $\mathrm{h}$ ). Immunohistochemical staining against phosphorylated $\mathrm{H} 2 \mathrm{AX}(\mathrm{\gamma H} 2 \mathrm{AX}-$ another marker for DNA breaks) confirmed these results (Figures $2 \mathrm{i}$ and j). Co-labeling of telomeres and $\mathrm{\gamma H} 2 \mathrm{AX}$ foci revealed a significant increase in telomere-induced DNA damage foci (TIFs) in the heterozygous knockout cohorts compared with wild-type controls (Figures $2 \mathrm{k}$ and $\mathrm{I}$ ).

Together, the current study provides the first experimental evidence that heterozygous gene deletion reduces the binding of Trf1 and Tin2 proteins at telomeres resulting in telomere fragility, DNA damage accumulation and enhanced lymphoma formation in aging mice, but not in premature aging per se. These results

Figure 1. Heterozygous loss of Trf1 and Tin2 leads to a dose-dependent reduction in expression, affects their binding to telomeres and leads to the enhanced formation of tumors during aging. (a and b) Quantitative analysis of Trf1 (a) and Tin2 (b) mRNA levels normalized to hydroxymethylbilane synthase in total spleen extracts of 14-16-month-old mice of the indicated genotypes. (c) Quantification of Tin2 protein expression levels relative to GAPDH by western blot analysis in total spleen protein extracts of 14-16-month-old mice of the indicated genotypes. (d) $\mathrm{Trf1}^{+/-}$and Tin2 ${ }^{+/-}$mice were crossed with HA-tagged Trf1 knockin mice (Trf ${ }^{\mathrm{ki} / k i}$ ). Western blot detection of a N-terminal HAtagged version of Trf1 ( ${ }^{\mathrm{HA}} \mathrm{mTrf1}$ ) and mTin2 after immunoprecipitation of ${ }^{\mathrm{HA}}$ Trf1 with an HA-specific antibody from protein extracts of testis of mice of the indicated genotypes. Western blot analysis of p84 was used as loading control. (e) Immuno-fluorescence in situ hybridization (FISH) staining of telomere-binding proteins (Trf1 and Tin2) and telomeric ends in mouse embryonic fibroblasts (MEFs) of the indicated genotypes. FISH of telomeric repeats was conducted using a [TTAGGG] 3 -Cy3 peptide nucleic acid (PNA) probe (red). Specific antibodies against the Shelterin proteins were used in combination with a secondary Alexa-488 labeled antibody (green). (f and $\mathbf{g})$ Percentage of co-localization of Trf1 (f) and Tin2 (g) foci at telomeric ends from MEFs of the indicated genotypes. (h) Kaplan-Meyer curves showing survival of wild-type mice $(n=26)$, Tin2 ${ }^{+/-}$mice $(n=21)$, $\operatorname{Trf} 1^{+/-}$mice $(n=32)$ and $\operatorname{Trf1} 1^{+/-} \operatorname{Tin}^{+/-}$mice $(n=33)$. The overall survival rate of the indicated genotypes is not significantly affected during the observation period of 140 weeks. (i) Quantification of the hematopoietic stem and progenitor cell compartment in 14-16-month-old mice by fluorescence activated cell sorting of the indicated genotypes. The percentages were calculated for viable in total bone marrow (panel I-III) ( $n=4-8$ mice per group). (j) Kaplan-Meyer curves showing tumor-free survival of the indicated mouse cohorts. Note that the heterozygous deletion of Trf1 and/or Tin2 reduced the latency of tumor formation. 18-24-monthold $\mathrm{Trf1}^{+/-}$mice, $\mathrm{Tin2}^{+/-}$mice and $\mathrm{Trf1}^{+/-} \mathrm{Tin2}^{+/-}$mice showed increased rates of tumor formation compared with wild-type mice developing tumors at 24-30 month. (k) Spectrum of the histological analyzed tumors. Malignant tumor formation is significantly enhanced in the knockout mice compared with the wild-type mice. Error bars indicate s.d. and the Student $t$-test was used for statistical calculations. (h and $\mathbf{j}$ ) the Mantel-Cox test was used for calculations of $P$-values. 
indicate that a tight control of the expression level of telomerebinding proteins is important to avoid tumor formation, but premature failure in organ homeostasis of patients carrying heterozygous TIN2 mutations likely involves gain of function or dominant negative effects of the mutant alleles as drivers of organ failure. Recent findings on reduced expression of telomere-binding proteins, telomere uncapping and increases in sister chromatid exchange rates in human lymphoma and in response to EpsteinBarr virus infection of human B-lymphocytes suggest that the results from this study are relevant for the development of human hematopoietic malignancies. ${ }^{7,14,15}$ Alterations in the expression level of telomere-binding proteins could represent an alternative, telomere length independent route to telomere dysfunction, which in turn induces hematopoietic malignancies. a

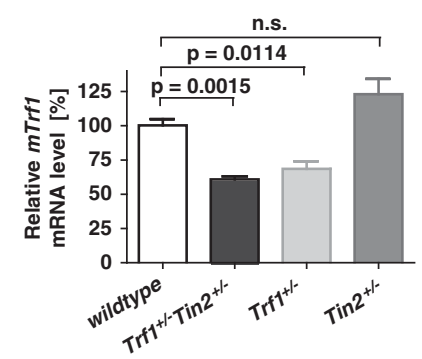

b

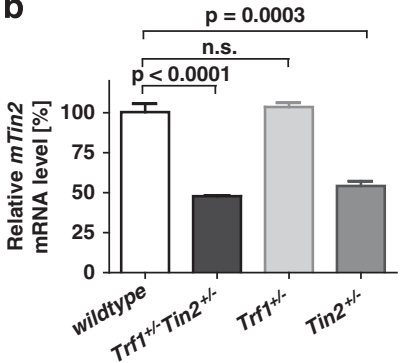

C

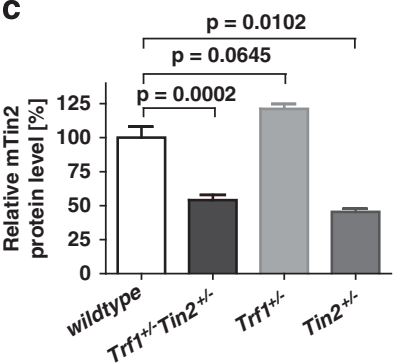

d

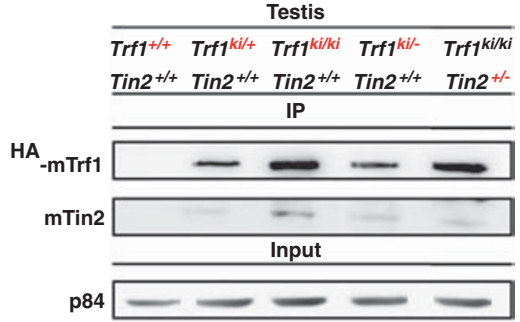

e

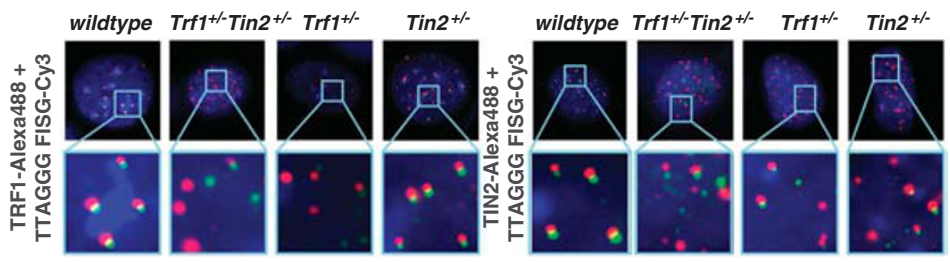

f

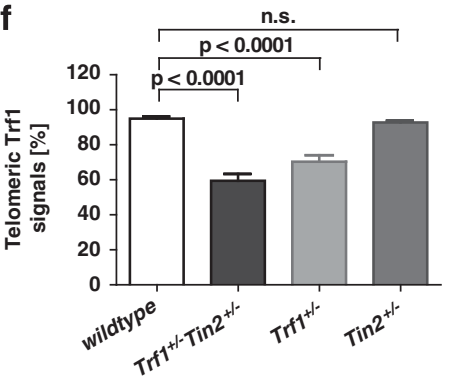

g

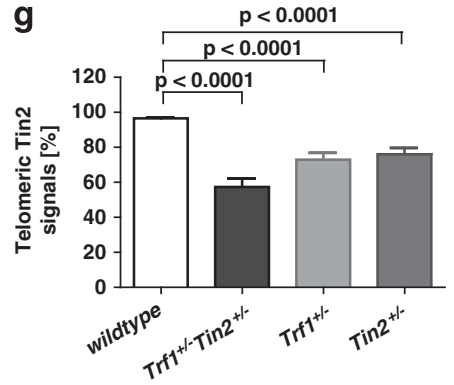

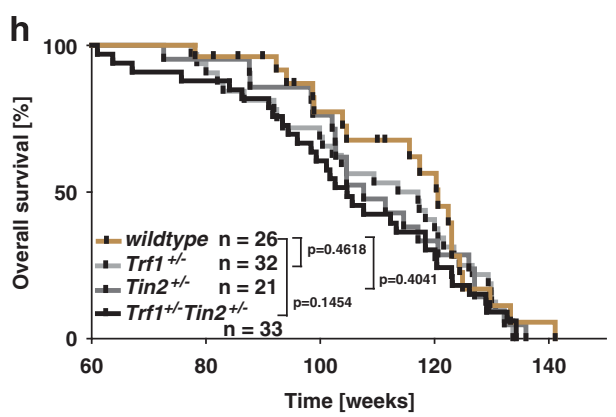
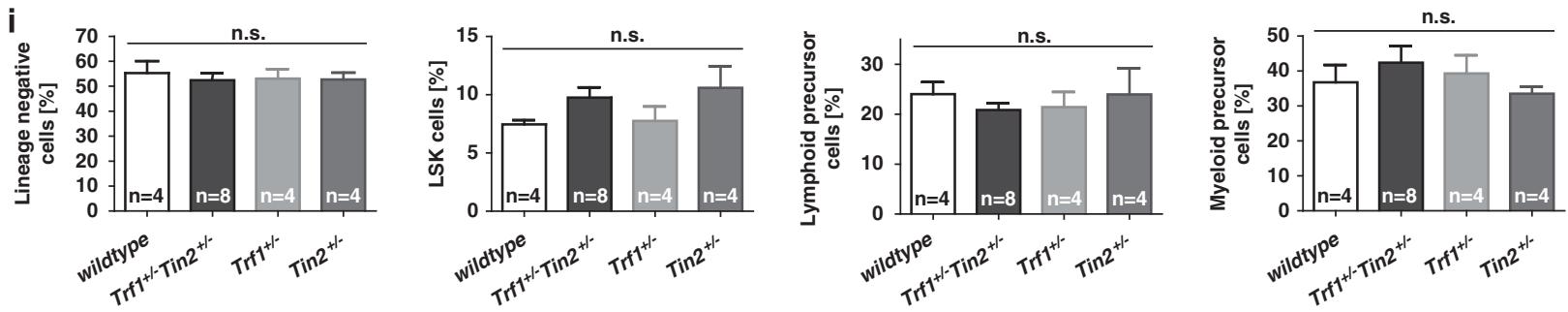

\section{j}

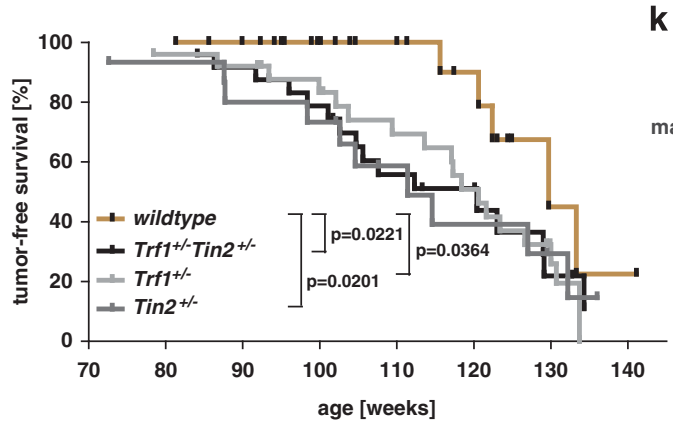

k

Wildtype

Knockout
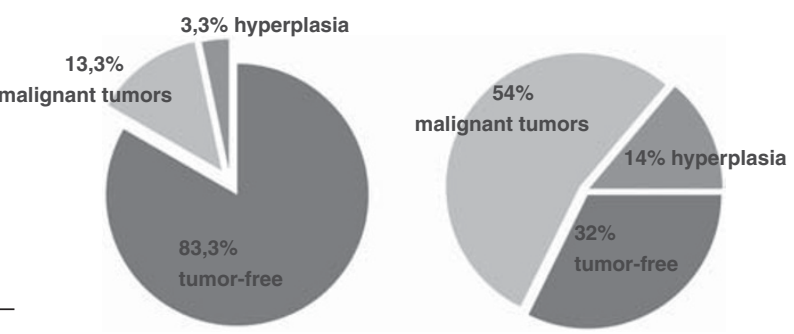


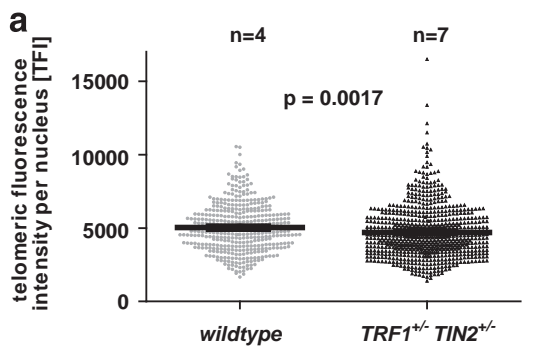

b

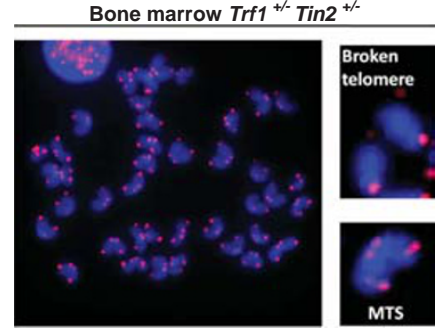

c
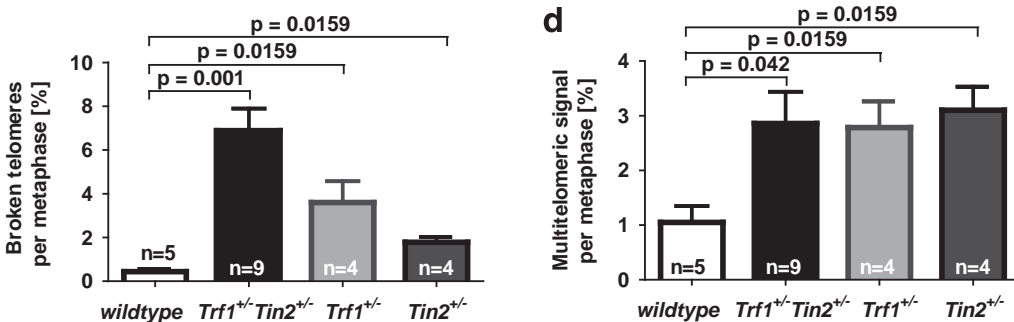

e
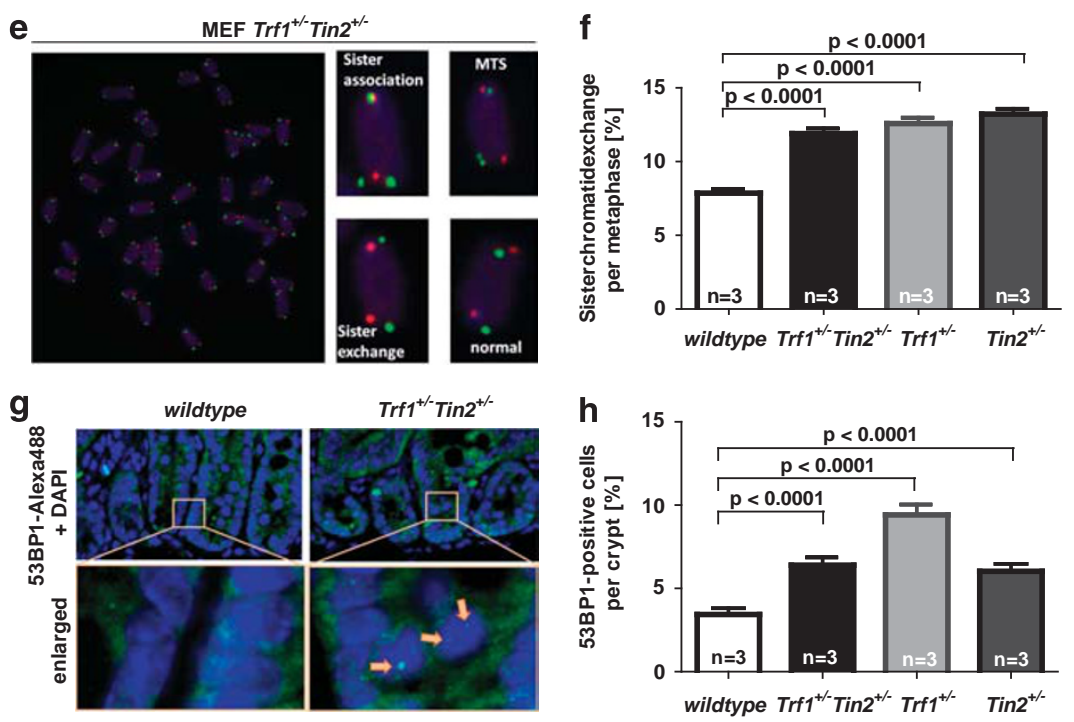

i

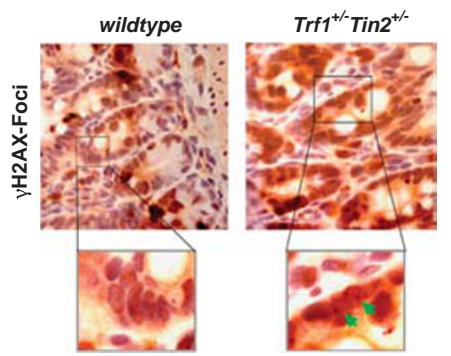

k

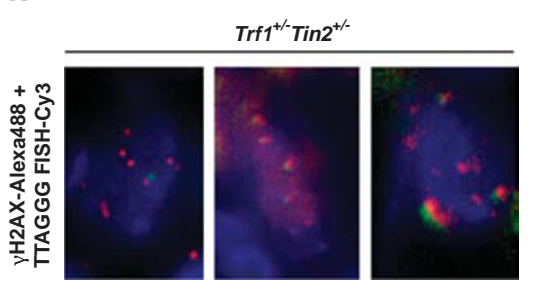

j
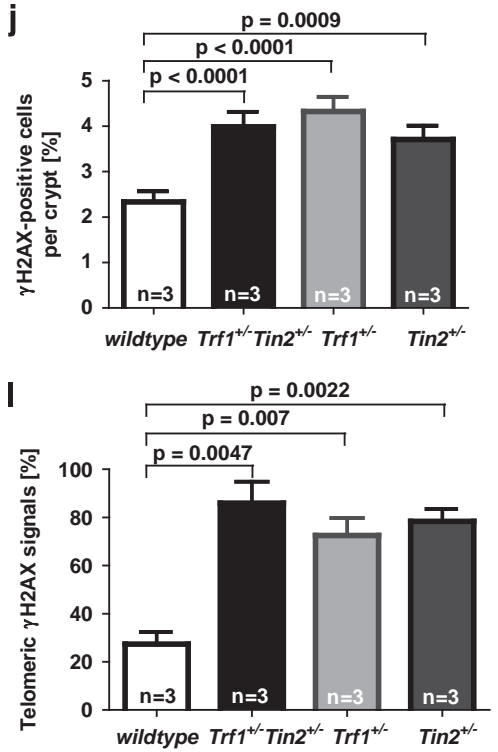
Figure 2. Trf1 and Tin2 deficiency leads to increased telomere fragility and sister chromatid exchange accompanied by an accumulation of DNA damage at telomeric ends in vivo. Metaphase spreads from freshly isolated bone marrow cells were analyzed by fluorescence in situ hybridization (FISH) using telomere specific probes: (a) the telomere fluorescence intensity (TFI) was quantified from 410 cells of wild-type mice and 728 cells of $\mathrm{Trf1}^{+/-} \mathrm{Tin2}^{+/-}$mice. The dot plot shows the mean TFI of individual nuclei. (b) Representative images of telomere fluorescence (Q-FISH) distribution in metaphase spreads from $\mathrm{Trf1}^{+/}-\mathrm{Tin}^{+/}{ }^{-}$mice using a [TTAGGG] $3_{3}$-Cy3 peptide nucleic acid (PNA) probe. High magnifications on the right show telomere fragility characterized by multitelomeric signals (lower picture) or broken telomeres (upper picture). (c and d) Quantification of the percentage of broken telomeres (c) and multitelomeric signals (d) per metaphase from bone marrow cells of the indicated genotypes. 144 individual metaphases of wild-type mice, 294 metaphases of Trf1 ${ }^{+1}{ }^{\text {Tin } 2^{+/-}}$mice, 204 metaphases of $\mathrm{Trf1}^{+/-}$mice and 236 metaphases of $\mathrm{Tin2}^{+/-}$mice have been analyzed. (e) Metaphase spreads from Trf1 ${ }^{+/-} \mathrm{Tin2}^{+/-}$mouse embryonic fibroblasts (MEFs) were analyzed by telomeric CO-FISH using a [TTAGGG] ${ }_{3}$-Alexa488 PNA probe (green) and a [CCCTAA] 3 -Cy3 PNA probe (red). High magnifications on the right show telomere fragility characterized by chromosomes with sister chromatid fusions (upper left), multitelomeric signals (upper right) or sister chromatid exchange (lower left). (f) Frequency of sister chromatid exchanges in metaphase spreads of MEFs from the indicated genotypes. 297 individual metaphases of wild-type mice, 316 metaphases of Trf1 ${ }^{+/-}$Tin2 $2^{+/-}$mice, 301 metaphases of $\mathrm{Trf1}^{+/-}$mice and 307 metaphases of $\mathrm{Tin}^{+/-}$mice have been analyzed. ( $\mathbf{g}$ and $\mathbf{h}$ ) Analysis of 53BP1 foci in the basal crypts of the small intestine from 14-16-month-old mice of the indicated genotypes: (g) representative images of 53BP1 foci in the basal crypts, (h) percentage of cells showing 53BP1 signals in the nuclei of crypt cells. In total, cells from 185 crypts of wild-type mice, 229 crypts of $\mathrm{Trf1}^{+/-}$Tin2 $^{+/-}$mice, 149 crypts of $\mathrm{Trf1}^{+/-}$mice and 146 crypts of Tin $2^{+/-}$mice have been analyzed. (i and $\mathbf{j}$ ) Analysis of $\gamma-\mathrm{H} 2 \mathrm{AX}$ foci in the basal crypts of the small intestine from 14-16-month-old mice of the indicated genotypes: (i) representative images of $\gamma$-H2AX foci in the basal crypts, (j) percentage of cells showing $\gamma-\mathrm{H} 2 \mathrm{AX}$ signals in the nuclei of crypt cells. In total, cells from 244 crypts of wild-type mice, 230 crypts of

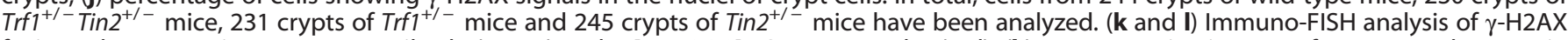
foci at telomeres using a $\gamma \mathrm{H} 2 \mathrm{AX}$ antibody (green) and a [TTAGGG] ${ }_{3}-\mathrm{Cy} 3 \mathrm{PNA}$ probe (red): (k) representative images of $\gamma \mathrm{H} 2 \mathrm{AXat}$ telomeres in crypts of $\mathrm{Trf1}^{+/-} \mathrm{Tin2}^{+/-}$knockout mice, (I) percentage of cells with co-localization of $\gamma$-H2AX foci at telomeres. $n=$ number of independent MEF cultures used per genotype. Error bars indicate s.d. and $P$-values are indicated. (c, $\mathbf{d}, \mathbf{f}$ and $\mathbf{j}$ ) the Mann-Withney test was used for calculations of $P$-values. (h and $\mathbf{I})$ The Student $t$-test was used for calculations of $P$-values.

\section{CONFLICT OF INTEREST}

The authors declare no conflict of interest.

\section{ACKNOWLEDGEMENTS}

We gratefully acknowledge Titia de Lange (Rockefeller University, NY, USA) for kind donation of antibodies and TRF1 deficient mice, Jeffrey Chiang and Richard Hodes for providing Tin2 knockout mice, as well as Leticia Quintanilla-Fend (University of Tübingen, Germany) for assistance with the lymphoma classification. This work was supported by the DFG (Ru745-10, RU-745-12), the European Union (ERC-2012-AdG 323136), the BMBF (GerontoSys-SyStaR 315894), the state of Thuringia, and intramural funds from the Leibniz association.

\section{AUTHOR CONTRIBUTIONS}

$\mathrm{KLR}$ and $\mathrm{KH}$ designed the research; $\mathrm{KH}, \mathrm{Al}, \mathrm{FL}$ and $\mathrm{AB}$ performed the research; $\mathrm{KH}, \mathrm{Al}$ and $\mathrm{FL}$ analyzed the data; $\mathrm{KH}$ and $\mathrm{KLR}$ wrote the paper.

\section{K Hartmann ${ }^{1}$, A Illing ${ }^{1,5}$, F Leithäuser ${ }^{2}$, A Baisantry ${ }^{1,6}$,} L Quintanilla-Martinez ${ }^{3}$ and KL Rudolph ${ }^{1,4}$

${ }^{1}$ Cooperation Group of the Leibniz Institute for Age Research - Fritz Lipmann Institute (FLI) Jena and UIm University (UULM), Ulm, Germany; ${ }^{2}$ Department of Pathology, University Hospital of UIm, Ulm, Germany;

${ }^{3}$ Institute of Pathology, University Hospital Tübingen, Tübingen, Germany and

${ }^{4}$ Faculty of Medicine, Research Group on Molecular Aging, University Hospital Jena (UKJ), Friedrich-Schiller-University (FSU), Jena, Germany E-mail: klrudolph@fli-leibniz.de

${ }^{5}$ Current address: Department of Internal Medicine, University Hospital of Ulm, Ulm, Germany.

${ }^{6}$ Current address: Department of Kidney, Liver and Metabolic Diseases, Children's Hospital, Hannover Medical School, Hannover, Germany.
4 Ramsay AJ, Quesada V, Foronda M, Conde L, Martinez-Trillos A, Villamor N et al. POT1 mutations cause telomere dysfunction in chronic lymphocytic leukemia. Nat Genet 2013; 45: 526-530.

5 Yamada M, Tsuji N, Nakamura M, Moriai R, Kobayashi D, Yagihashi A et al. Down-regulation of TRF1, TRF2 and TIN2 genes is important to maintain telomeric DNA for gastric cancers. Anticancer Res 2002; 22: 3303-3307.

6 Yamada K, Yagihashi A, Yamada M, Asanuma K, Moriai R, Kobayashi D et al. Decreased gene expression for telomeric-repeat binding factors and TIN2 in malignant hematopoietic cells. Anticancer Res 2002; 22: 1315-1320.

7 Kamranvar SA, Chen X, Masucci MG. Telomere dysfunction and activation of alternative lengthening of telomeres in B-lymphocytes infected by EpsteinBarr virus. Oncogene 2013; 32: 5522-5530.

8 Lajoie V, Lemieux B, Sawan B, Lichtensztejn D, Lichtensztejn Z, Wellinger R et al. LMP1 mediates multinuclearity through downregulation of shelterin proteins and formation of telomeric aggregates. Blood 2015; 125: 2101-2110.

9 Karlseder J, Kachatrian L, Takai H, Mercer K, Hingorani S, Jacks T et al. Targeted deletion reveals an essential function for the telomere length regulator Trf1. Mol Cell Biol 2003; 23: 6533-6541.

10 Chiang YJ, Kim SH, Tessarollo L, Campisi J, Hodes RJ. Telomere-associated protein TIN2 is essential for early embryonic development through a telomeraseindependent pathway. Mol Cell Biol 2004; 24: 6631-6634.

11 Beier F, Foronda M, Martinez P, Blasco MA. Conditional TRF1 knockout in the hematopoietic compartment leads to bone marrow failure and recapitulates clinical features of Dyskeratosis congenita. Blood 2012; 120: 2990-3000.

12 Martinez P, Thanasoula M, Munoz P, Liao C, Tejera A, McNees C et al. Increased telomere fragility and fusions resulting from TRF1 deficiency lead to degenerative pathologies and increased cancer in mice. Genes Dev 2009; 23: 2060-2075.

13 Rudolph KL, Chang S, Lee HW, Blasco M, Gottlieb GJ, Greider C et al. Longevity, stress response, and cancer in aging telomerase-deficient mice. Cell 1999; 96: 701-712.

14 Knecht H, Sawan B, Lichtensztejn D, Lemieux B, Wellinger RJ, Mai S. The 3D nuclear organization of telomeres marks the transition from Hodgkin to ReedSternberg cells. Leukemia 2009; 23: 565-573.

15 Lacoste S, Wiechec E, Dos Santos Silva AG, Guffei A, Williams G, Lowbeer M et al. Chromosomal rearrangements after ex vivo Epstein-Barr virus (EBV) infection of human B cells. Oncogene 2010; 29: 503-515.

\section{REFERENCES}

1 Palm W, de Lange T. How shelterin protects mammalian telomeres. Annu Rev Genet 2008; 42: 301-334.

2 Dokal I. Dyskeratosis congenita. Hematology Am Soc Hematol Educ Program 2011; 2011: 480-486.

3 Walne AJ, Bhagat T, Kirwan M, Gitiaux C, Desguerre I, Leonard N et al. Mutations in the telomere capping complex in bone marrow failure and related syndromes. Haematologica 2013; 98: 334-338.

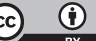

This work is licensed under a Creative Commons Attribution 4.0 International License. The images or other third party material in this article are included in the article's Creative Commons license, unless indicated otherwise in the credit line; if the material is not included under the Creative Commons license, users will need to obtain permission from the license holder to reproduce the material. To view a copy of this license, visit http://creativecommons.org/licenses/ by/4.0/

Supplementary Information accompanies this paper on the Leukemia website (http://www.nature.com/leu) 